\title{
BMJ Open Second opinion utilization by healthcare insurance type in a mixed private-public healthcare system: a population-based study
}

\author{
Liora Shmueli, ${ }^{\oplus 1}$ Erez Shmueli, ${ }^{2}$ Joseph S Pliskin,, ${ }^{3,4}$ Ran D Balicer, ${ }^{5,6}$ \\ Nadav Davidovitch, ${ }^{4}$ Igal Hekselman, ${ }^{7,8}$ Geva Greenfield ${ }^{9}$
}

To cite: Shmueli L, Shmueli E, Pliskin JS, et al. Second opinion utilization by healthcare insurance type in a mixed private-public healthcare system: a populationbased study. BMJ Open 2019;9:e025673. doi:10.1136/ bmjopen-2018-025673

- Prepublication history and additional material for this paper are available online. To view these files, please visit the journal online (http://dx.doi org/10.1136/bmjopen-2018025673).

Received 17 September 2018 Revised 28 May 2019 Accepted 3 July 2019

Check for updates

(C) Author(s) (or their employer(s)) 2019. Re-use permitted under CC BY-NC. No commercial re-use. See rights and permissions. Published by BMJ.

For numbered affiliations see end of article.

Correspondence to

Dr Liora Shmueli;

liora.jana@gmail.com

\section{ABSTRACT}

Objectives To evaluate the utilisation (overall and by specialty) and the characteristics of second-opinion seekers by insurance type (either health fund or supplementary insurance) in a mixed private-public healthcare.

Design An observational study.

Setting Secondary care visits provided by a large public health fund and a large supplementary health insurance in Israel.

Participants The entire sample included 1392907 patients aged 21 years and above who visited at least one specialist over an 18 months period, either in the secondary care or privately via the supplementary insurance.

Outcomes measures An algorithm was developed to identify potential second-opinion instances in the dataset using visits and claims data. Multivariate logistic regression was used to identify characteristics of secondopinion seekers by the type of insurance they used. Results $143371(13 \%)$ out of 1080892 patients who had supplementary insurance sought a single second opinion, mostly from orthopaedic surgeons. Relatively to patients who sought second opinion via the supplementary insurance, second-opinion seekers via the health fund tended to be females $(\mathrm{OR}=1.2,95 \% \mathrm{Cl} 1.17$ to 1.23$)$, of age $40-59$ years $(\mathrm{OR}=1.36,95 \% \mathrm{Cl} 1.31$ to 1.42$)$ and with chronic conditions ( $\mathrm{OR}=1.13,95 \% \mathrm{Cl} 1.08$ to 1.18$)$. In contrast, second-opinion seekers via the supplementary insurance tended to be native-born and established immigrants $(\mathrm{OR}=0.79,95 \% \mathrm{Cl} 0.76$ to 0.84$)$, in a high socioeconomic level $(\mathrm{OR}=0.39,95 \% \mathrm{Cl} 0.37$ to 0.4$)$ and living in central areas $(\mathrm{OR}=0.88,95 \% \mathrm{Cl} 0.85$ to 0.9$)$. Conclusions Certain patient profiles tended to seek second opinions via the supplementary insurance more than others. People from the centre of the country and with a high socioeconomic status tended to do so, as medical specialists tend to reside in central urban areas. Further research is recommended to examine the availability of medical specialists by specialty and residence.

\section{INTRODUCTION}

The role of private-public mixed (PPM) healthcare systems in the development and operation of healthcare services has recently

\section{Strengths and limitations of this study}

- This study presents a large-scale population analysis based on an innovative algorithm.

- This study is based on an innovative linkage between rarely linked datasets: universal insurance data and supplementary insurance, containing data on private consultations.

- All previous studies that evaluated second-opinion utilisation used self-reported surveys with relatively small samples.

- Lack of data from private health insurances.

drawn interest from researchers and policy makers, as the private sector affects and shapes the public sector and vice versa. ${ }^{1}$ Some countries in the USA and Europe adopted public-private partnerships, mainly in order to cope with growing healthcare expenditures, especially those of the private health system. ${ }^{23}$ Most of these partnerships maintain clear boundaries between the public and the private sector. Yet, in some countries having PPM, these boundaries are not always clear in aspects of funding and provision (eg, in Israel and the Netherlands). The lack of clarity between private and public may increase inequalities, especially when certain services are available only for those who are able to purchase them privately by out-of-pocket payments.

Healthcare organisations have an important role in reducing health inequalities caused by access to quality medical care among other things. ${ }^{45}$ One of the debates in countries having PPM and National Health Insurance (NHI) is what services should be provided by the NHI, bearing in mind that national tax-funded baskets are limited in their budgets and services. ${ }^{6-8}$ Moreover, how to provide a service within a funded basket without creating overuse becomes 
a challenge, including controversial literature on what is proper use of healthcare services. A recent initiative called Choosing Wisely, promoted in various countries, seeks to advance a national dialogue on avoiding unnecessary medical tests, treatments and procedures. ${ }^{9}$

Consultations with specialists can serve as an example for such a service in question, since different policies were implemented by various countries having NHI: France and Japan, entail high copayments for specialists in order to avoid overutilisation while other countries, such as Great Britain, limit copayments for specialists. In Great Britain, choice of specialists is limited and long waiting lists for specialists have become a serious problem. ${ }^{10}$ In order to cope with these problems, Great Britain offers a supplementary free-market private health insurance. ${ }^{11}$

One typical use of consultation with specialists is for getting a second opinion ( $\mathrm{SO}$ ). Previous studies have shown the clinical importance of SOs, especially in light of discrepancies in clinical judgement, ${ }^{12-17}$ and their potential to reduce unnecessary surgical procedures,${ }^{18-22}$ which may lead to reduced costs. There are three main types of SO: the most common type of $\mathrm{SO}$ is initiated by patients to consult with another physician for an additional opinion on a diagnosis, treatment or prognosis, ${ }^{23}$ this study focuses on the first type. The second type, initiated by the physician, who is looking for the advice of a second specialist. The third type, related to SO programmes usually imposed, on patients and doctors alike, by thirdparty insurers as a cost containment measure. ${ }^{11}$

Exploring SO utilisation by healthcare insurance type can serve as a case study for understanding the PPM in healthcare and its influence on the development and operation of SOs. Moreover, differences in access to healthcare services such as $\mathrm{SO}$ can also explain health inequalities, especially when it comes to paying out of pocket.

\section{Second opinion utilisation by healthcare insurance in the world}

There are major differences among countries in health policy, regulatory arrangements and insurance types, which define access, provision and payment mechanisms for SOs.

In the last decades, SOs evolved from an insurer requirement derived from financial considerations to a patient's right ${ }^{24} 25$ and many patients are likely to obtain an SO, especially on serious diagnoses. ${ }^{26} \mathrm{~A}$ debate still exists whether SOs are a right or a concession and how insurers should cover them.

In a market characterised mostly as private such as the US, SOs in many cases serve as a cost control tool, where health insurance plans require and provide mandatory SOs for surgery. SO programmes were first introduced in the US in the 1970s by insurance companies as a pre-authorisation tool before elective surgery. ${ }^{27}$

The Medicare Health Maintenance Organisation (HMO), which covers about $13 \%$ of the population, provides SOs in some cases before surgery with copayment and will pay $80 \%$ of the cost. Some plans in the US require a referral from the primary care physician and require seeing an in-network physician. ${ }^{28}$ Conversely, in countries having NHI such as Canada, there is no mandatory SO requirement for surgery ${ }^{29}$ and in some other countries in Europe it is not a formal right. For example, in the UK, patients do not have a legal right to an SO, although a healthcare professional will rarely refuse to refer them for one. ${ }^{30}$ Only few studies examined the characteristics of patients seeking an SO by insurance type or coverage policy. The only finding relating to insurance type shows that among HMO enrollees with private insurance, the odds of getting an $\mathrm{SO}$ were 2.7 times greater than they were for HMO enrollees with public insurance..$^{25}$ Another study reports that one of the only predictors of remaining at the SO site was insurance type. ${ }^{31}$

\section{Second opinion in the Israeli healthcare system}

In Israel, patients are legally entitled to obtain SOs according to the Patient Rights Law (1996), but there is no government coverage for this entitlement in the NHI Law (1995) or in any other laws.

The Israeli healthcare system consists of four non-profit health funds providing primary and secondary care. The health funds also provide supplementary health insurance services that demand extra payment, based mainly on age (in contrary to NHI, funded by health taxes). Seventy-five per cent of Israelis had supplementary health insurance services by $2011 .^{32}$ The supplementary insurance provides complementary services (eg, complementary medicine, cosmetics) and supplementary services (eg, SO, choice of physicians, etc) that are not included in the national public basket. ${ }^{333}$

With respect to $\mathrm{SO}$, patients in Israel can in practice obtain SOs in three ways.

First, patients can obtain SOs through the supplementary health insurance programmes. Patients are eligible to partial reimbursement for out-of-pocket SO consultations with private specialists (up to $80 \%$ of the out-ofpocket cost, limited by the upper bound of approximately US $\$ 130$ per consultation. The cost of a private consultation typically ranges between US\$200 and US\$500). This reimbursement is quite similar across the four health funds. The supplementary health insurance offered by 'Clalit Health Services' (the largest health fund in Israel), also provided a unique service called 'consultants network', which allowed to consult with specific specialists (who work under contract with the health fund) for SO and pay a copayment of US\$33 (updated to 2011, as of this study period) directly to the consultant. SO consultations through the supplementary health insurance programmes are limited up to a maximum of three per calendar year.

Second, patients can get an SO through the private sector and pay out-of-pocket and receive a partial reimbursement by private insurance companies. ${ }^{34}$

Third, patients can get an SO through the secondary care provided by the health funds themselves. Although 
SO is not included in the basic basket, patients can approach specialists working in the community by paying (approximately) a US\$6 quarterly copayment for the same specialist for a 3 months period, with no limitation on the number of visits.

In this paper, we focus on the first and third insurance types (the supplementary health insurance and the health fund), as it is much more complicated to obtain data from private insurance companies (there is a large number of such companies, and each company store the relevant information in a different format).

It is not clear how many SOs are funded by each of these two sources, which differ substantially in their equity implications, and what are the characteristics of the SO seekers in each case. Moreover, it is important to explore whether there exist such differences between the two insurance types in specific specialties, which may indicate differences in supply of services between the two insurance types in these specialties.

The need to better understand these aspects becomes even stronger due to the sharp increase in demand for SOs in Israel via the supplementary health insurance programmes and the increase in their total net expenditure by $>50 \%$ from 2006 to $2010 .^{35}$ This rise reflects the shift from pure private encounters to a privatepublic mix characterising the supplementary insurance environment. ${ }^{3}$

To the best of our knowledge, all studies that evaluated SO utilisation so far were based on patient self-reported surveys and not on objective data, which makes it difficult to compare among different studies and countries. A recent systematic review stresses the need for standardised methods and outcome measures. ${ }^{36}$ The lack of objective data on SO utilisation by insurance type drove us to conduct a quantitative measurement of SO utilisation in a large-scale population.

\section{Objectives}

To evaluate the utilisation (overall and by specialty) and the characteristics of SO seekers by insurance type (either health fund or supplementary insurance) in a mixed private-public healthcare.

\section{METHODS}

\section{Data sources}

This study is based on the same data used in the study by Shmueli et $a l^{37}$ which was provided to us by 'Clalit Health Services'. Clalit Health Services is the largest health fund in Israel, covering 52\% of the Israeli population ( $>4.5$ million, second largest in the world after Kaiser Permanente) and providing primary, secondary and tertiary care. We used two datasets which were linked by a patient identifier and by a physician identifier (health fund; supplementary insurance services) in order to analyse: (1) consultations with specialists in the community secondary care and (2) claims of out-ofpocket costs of private consultations, claimed from the health fund's supplementary insurance services. The datasets also included patient demographics.

\section{Study population}

We applied the same inclusion and exclusion criteria that were used in the study by Shmueli et $a .^{37}$ The inclusion criteria were: (1) being an active member of 'Clalit Health Services' (active between 1 September 2009 and 30 April 2011); (2) age 21 years and above; (3) visited between 1 September 2009 and 30 April 2011 at least one specialist, either in the secondary care provided by the HMO in the community, or a private consultation claimed from the HMO's supplementary insurance services, in one of the following domains: orthopaedics, ophthalmology, dermatology, ear, nose and throat (ENT), cardiology, general surgery, urology, gastroenterology and neurology. We chose these specialties following a preliminary descriptive analysis, showing that these domains account for the vast majority of consultations. The exclusion criteria were: (1) patients who only visited a family physician; (2) patients who did not consult with a specialist in the above list; (3) treatment or medical procedure visits (ie, non-clinical consultations) and (4) patients who died during the study period.

\section{Variables and measurements}

We defined a 'second medical opinion' instance as 'consulting with another specialist, in the same specialty, within 3 months of the first consultation in order to get an SO for the same medical problem'.

Since our dataset did not have an explicit field indicating whether a visit to a physician constitutes an $\mathrm{SO}$ or not, we applied a dedicated algorithm to identify SO instances. The algorithm was first suggested by us in the study by Shmueli et $a \vec{l}^{37}$ and was used there to evaluate SO utilisation rates. A detailed description of the algorithm as well as a running example illustrating the main stages of the algorithm (figure 1) are shown in online supplementary appendix I.

Each SO instance identified by the algorithm includes a pair of visits-the first consultation of a patient with a specialist (the 'first opinion') and a consultation with another specialist (the 'second opinion'). Each 'pair' of a first opinion and an $\mathrm{SO}$ could take place in four possible combinations: (1) both first opinion and SO provided via the health fund; (2) both first opinion and SO provided via a supplementary insurance; (3) first opinion provided via the health fund and SO via the supplementary insurance; (4) first opinion via the supplementary insurance and SO provided via the health fund.

The dependent binary variable was the setting where the SO was obtained. It could be at the community secondary care provided by the health fund, or a private consultation claimed via the supplementary insurance.

The covariates included patient demographics: (1) age; (2) gender; (3) being an immigrant (defined as immigration to Israel after 1989, the years of mass immigration mainly from the former USSR); (4) socioeconomic level 
\# Algorithm step

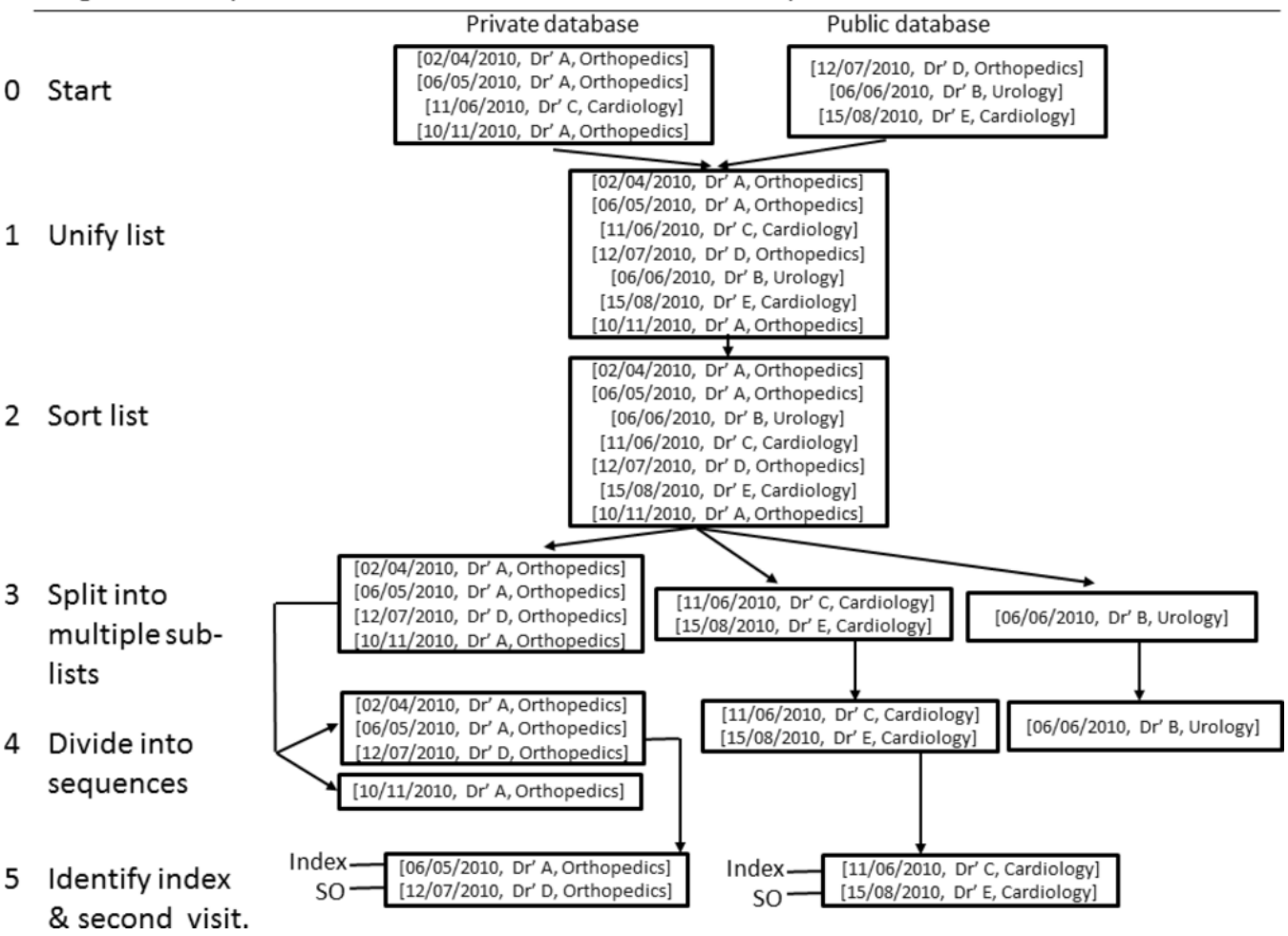

Figure 1 A time-sensitive algorithm for identifying second-opinion consultations.

(according to the Israeli Central Bureau of Statistics). We clustered the original 10 groups of socioeconomic levels, grouped into three levels: low, medium and high; (5) Charlson Comorbidity Score (without age)-the most widely used clinical index for the evaluation of comorbidities. The score is based on a weighted index that considers the seriousness of a comorbid disease. Scores were grouped into four levels: $0,1-2,3-4$ and $>5^{38}$; (6) 'periphery' level. The 'periphery' level (according to the Israeli Central Bureau of Statistics) is based on a peripheral index which combines two components: potential accessibility index of the local authority and proximity of the local authority to the boundary of the Tel Aviv district (www.cbs.gov.il). The peripheral index included local authorities that were classified into 10 clusters. We grouped those clusters based on their periphery distribution scale into three groups: peripheral, intermediate and central.

\section{Statistical analyses}

Descriptive statistics of the independent variables were calculated for the overall population of members who had sought one SO. We then compared the characteristics of patients who sought an SO from a physician through the health fund with those who sought an SO through the supplementary insurance using univariate $\chi^{2}$ tests. We applied the procedure suggested by Kraemer et al, ${ }^{39}$ to reduce the level of collinearity in the model and consequently to prevent misinterpretations of the fitted model's results. More specifically, we checked correlations between each pair of variables, and excluded the religion variable as it was found to be highly correlated with the socioeconomic variable $(\mathrm{r}=-0.599)$. A multivariate logistic regression model was examined as an adjusted full model to assess the association between $\mathrm{SO}$ seeking by insurance type and the covariates. We created dummy variables for all of the categorical variables (age, socioeconomic level and Charlson Comorbidity Score). We entered into the multivariate logistic regression only variables that were significant $(\mathrm{p}<0.05)$ in the univariate tests. We used the ENTER elimination method for model selection. The threshold for elimination was 0.05 . We used SPSS V.23 for the statistical analyses.

\section{Patient involvement}

Since this study is based on the analysis of electronic medical records and is not a clinical research, patients were not involved at any stage of the study.

\section{FINDINGS}

The total number of patients included in our dataset was 1392907 (figure 2). Out of these patients, we kept only the $78 \%$ who had a supplementary insurance ( $\mathrm{n}=1080$ 892). The rationale for keeping only these patients was that we wanted to compare between patients who chose to obtain SO via the health fund and those who chose to use the supplementary health insurance. Since patients who did not have a supplementary insurance could not choose to use it, we decided to filter them out.

Sixteen per cent $(n=176306)$ of the patients who had supplementary insurance sought at least one SO during 


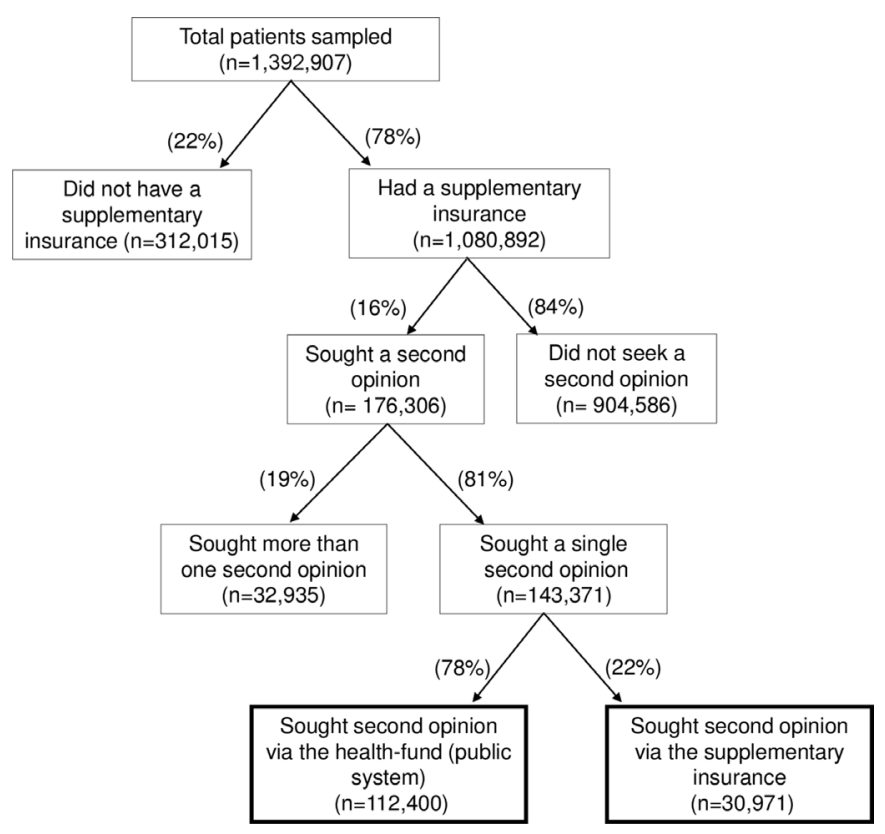

Figure 2 Study population: patients sought a second opinion by insurance type: health fund vs supplementary insurance.

the study period and the remaining $84 \%$ of the patients did not seek an SO (a detailed description of their characteristics appears in a previous study of ours ${ }^{37}$ ). It is important to note that the electronic medical records of patients did not include an explicit field indicating whether a visit is an $\mathrm{SO}$ or not, and therefore we had to extract the records of all patients mentioned above and exclude patients who did not have an SO by applying our dedicated algorithm.

From the remaining 176306 patients, we excluded 19\% of the patients $(n=32935)$ who had more than one SO during the study period, and kept $81 \%$ of the patients $(n=143371)$ who had exactly one SO. This exclusion was done in order to be able to categorise patients such that they had their SO visit provided by the health fund and by the supplementary insurance. In contrast, patients who had more than one SO could have had one SO visit provided by the health fund and another by the supplementary insurance. We refer to these 143371 patients as 'the target population'.

\section{Who sought a second opinion by insurance type: health fund versus supplementary insurance?}

Table 1 presents the characteristics of patients who sought an SO via health fund versus supplementary insurance. Out of the entire target population $(n=143371)$, most were female $(57 \%, \mathrm{n}=81531)$, were native-born Israelis or established immigrants $(92 \%, \mathrm{n}=131484)$, were classified as middle socioeconomic status $(59 \%, \mathrm{n}=84129)$, were living in central residential areas $(62 \%, 88$ 176), were above age $60(49 \%, 69581)$ and were classified as not having any chronic disease by the Charlson Comorbidity Score $(42 \%, \mathrm{n}=60820)$.
The univariate analyses showed significant differences $(\mathrm{p}<0.05)$ between people who sought an SO via the health fund and those who sought an SO via the supplementary insurance, in age group, gender, immigration, socioeconomic level, peripheral level and Charlson Comorbidity Score (table 1).

Table 2 presents the results of the multivariate logistic regression analysis (reference group of each covariate are marked with a star). The significant covariates from the univariate analyses that remained significant in the multivariate logistic regression are: age group, gender, immigration, socioeconomic level and peripheral level, Charlson Comorbidity Score (except the 1-2 level). More specifically, women ( $\mathrm{OR}=1.2,95 \%$ CI 1.17 to 1.23$)$, people aged $40-59$ years ( $\mathrm{OR}=1.36,95 \%$ CI 1.31 to 1.42$)$ and those with chronic conditions $(\mathrm{OR}=1.13,95 \%$ CI 1.08 to 1.18) sought more SOs via the health fund than via the supplementary insurance. Old people $(\mathrm{OR}=0.62,95 \% \mathrm{CI}$ 0.6 to 0.64 ), native-born and established immigrants $(\mathrm{OR}=0.79,95 \%$ CI 0.76 to 0.84$)$, people in a middle socioeconomic level (OR=0.55, 95\% CI 0.53 to 0.57$)$ and in a high socioeconomic level ( $\mathrm{OR}=0.39,95 \%$ CI 0.37 to 0.4 ) and those living in central areas $(\mathrm{OR}=0.88,95 \%$ CI 0.85 to 0.9 ) sought less SOs via the health fund than via the supplementary insurance.

\section{Second opinion utilisation by specialty and insurance type}

Table 3 presents the total number of consultations and SO rates (in parentheses) by specialties for the two insurance types. The rate of $\mathrm{SO}$ consultations for each specialty was calculated by dividing the number of SO consultations by the total number of consultations in that specialty. This was done in order to avoid cases of a high SO rate that is simply a result of a large number of consultations in a given specialty.

The highest proportion of SO consultations were sought from orthopaedic surgeons $(17 \%)$ via both the health fund and the supplementary insurance. Other specialties with high SO utilisation were ENT, general surgery and ophthalmology, all presented a similar rate in the two insurance types.

\section{DISCUSSION}

\section{Summary of main findings}

Sixteen per cent of the patients who had supplementary insurance sought at least one SO during the study period. Particular patient profiles tend to seek SOs via the health fund rather than the supplementary insurance: women, people aged 40-59 years, immigrants, people in a low socioeconomic level, those living in periphery areas and those with chronic conditions. The highest proportion of SO consultations were sought from orthopaedic surgeons, both via the health fund and supplementary insurance.

\section{Challenges raised by the findings}

Although most of the SO seekers had a supplementary insurance which enables them reimbursement for private 
Table 1 Characteristics of patients in the target population who sought a second opinion via health fund vs supplementary insurance $(n=143371)$

\begin{tabular}{|c|c|c|c|}
\hline \multirow[b]{2}{*}{ Characteristics } & Health fund & Supplementary insurance & \multirow[b]{2}{*}{$P$ value } \\
\hline & $\mathrm{n}=112400(\%)$ & $\mathrm{n}=30971(\%)$ & \\
\hline \multicolumn{4}{|l|}{ Age group (years) } \\
\hline $18-39$ & $28330(25.2)$ & $6679(21.6)$ & $<0.001$ \\
\hline $40-59$ & $33346(29.7)$ & $5435(17.5)$ & \\
\hline $60+$ & $50724(45.1)$ & $18857(60.9)$ & \\
\hline \multicolumn{4}{|l|}{ Gender } \\
\hline Male & $47496(42.3)$ & $14344(46.3)$ & $<0.001$ \\
\hline Female & $64904(57.7)$ & $16627(53.7)$ & \\
\hline \multicolumn{4}{|l|}{ Immigration } \\
\hline Immigrants & $9874(8.8)$ & $2013(6.5)$ & $<0.001$ \\
\hline Native-born and established immigrants & $102526(91.2)$ & $28958(93.5)$ & \\
\hline \multicolumn{4}{|l|}{ Socioeconomic level } \\
\hline Low & $27014(24.0)$ & $4025(13.0)$ & $<0.001$ \\
\hline Middle & $65734(58.5)$ & $18395(59.4)$ & \\
\hline High & $19652(17.5)$ & $8551(27.6)$ & \\
\hline \multicolumn{4}{|l|}{ Periphery level } \\
\hline Periphery of country & $44934(40.0)$ & $10261(33.1)$ & $<0.001$ \\
\hline Centre of country & $67466(60.0)$ & $20710(66.9)$ & \\
\hline \multicolumn{4}{|l|}{ Charlson Comorbidity Score } \\
\hline 0 & $48515(43.2)$ & $12305(39.7)$ & $<0.001$ \\
\hline $1-2$ & 43931 (39.1) & $12583(40.6)$ & \\
\hline $3-4$ & $13386(11.9)$ & 4168 (13.5) & \\
\hline $5-25$ & $6568(5.8)$ & $1915(6.2)$ & \\
\hline Total & 112400 & 30971 & \\
\hline
\end{tabular}

${ }^{*}$ Percentages are calculated as valid \% per each variable in the column (ie, each variable in the column sums up to $100 \%$, without missing values).

consultations, they have mostly obtained their SO via the health fund, which is an underutilisation of their supplementary insurance. Differences in profiles of SO seekers through the public and private system may explain why certain people with supplementary insurance do not use their entitlement for private SOs.

In Israel, the boundaries between the public and private systems are not clear. The public health funds are allowed to market supplementary health insurance ${ }^{378}$ and there are cases in which the same physicians were allowed to provide medical consultations under both private and public contracts. ${ }^{7}$ There are some cases where in order to shorten waiting times to a specialist within the secondary public system, some patients use their supplementary insurance and pay a copayment for ' $\mathrm{SO}$ consultation service', although they did not seek an SO in practice. ${ }^{40}$

Another explanation is the impact of socioeconomic level, as a proxy to the ability to pay privately, which was evident in our findings. Income is a familiar social determinant associated with health disparities. ${ }^{41}$ High-income groups opt to use private health services ${ }^{42}$ and those with a higher socioeconomic status consult with more specialists. ${ }^{43}$ Even with the partial reimbursement for private consultations, these consultations might still be expensive to many people. Likewise, the entitlement is for three private consultations in a year, which may lead the less affluent to 'cherry pick' the private consultation to only cases they are most concerned about. There is evidence to suggest that copayments have created financial barriers to access, particularly for people with low incomes. ${ }^{44}$ In $2014,11 \%$ of the adult population refrained from taking medicines or visiting physicians within the NHI because of copayments or coinsurances.

Another possible explanation for the difference in profiles of SO seekers is the geographical context. Medical specialists tend to have their office locations close to hospitals located in central areas. ${ }^{45}$ Our findings show that those living in central areas sought more $\mathrm{SO}$ in the private sector. It is also consistent with a Canadian study, showing that residents of the most urban centres were more likely to use specialist services. ${ }^{46} \mathrm{~A}$ study conducted in Japan and the USA explained why 
Table 2 Characteristics associated with seeking a second opinion by insurance type utilisation (health fund vs supplementary insurance) of the target population

\begin{tabular}{|c|c|c|}
\hline Covariates & $\operatorname{Exp}(B)^{*}(95 \% \mathrm{Cl})$ & $P$ value \\
\hline \multicolumn{3}{|l|}{ Gender } \\
\hline Male* & Reference & \\
\hline Female & 1.20 (1.17 to 1.23$)$ & $<0.001$ \\
\hline \multicolumn{3}{|l|}{ Immigration } \\
\hline Immigrants* & Reference & \\
\hline $\begin{array}{l}\text { Native-born and } \\
\text { established immigrants }\end{array}$ & $0.79(0.75$ to 0.84$)$ & $<0.001$ \\
\hline \multicolumn{3}{|l|}{ Age group (years) } \\
\hline $18-39^{*}$ & Reference & \\
\hline $40-59$ & $1.36(1.31$ to 1.42$)$ & $<0.001$ \\
\hline $60+$ & $0.62(0.60$ to 0.64$)$ & $<0.001$ \\
\hline \multicolumn{3}{|l|}{ Socioeconomic level } \\
\hline Low $^{*}$ & Reference & \\
\hline Middle & 0.55 (0.53 to 0.57$)$ & $<0.001$ \\
\hline High & 0.39 (0.37 to 0.40$)$ & $<0.001$ \\
\hline \multicolumn{3}{|l|}{ Periphery level } \\
\hline Periphery of country* & Reference & \\
\hline Centre of country & 0.88 (0.85 to 0.90$)$ & $<0.001$ \\
\hline \multicolumn{3}{|l|}{$\begin{array}{l}\text { Charlson Comorbidity } \\
\text { Score }\end{array}$} \\
\hline $0^{*}$ & Reference & \\
\hline $1-2$ & 1.03 (0.99 to 1.06$)$ & 0.089 \\
\hline $3-4$ & 1.13 (1.08 to 1.18$)$ & $<0.001$ \\
\hline $5-25$ & $1.28(1.21$ to 1.36$)$ & $<0.001$ \\
\hline
\end{tabular}

${ }^{*}$ Reference $\operatorname{Exp}(\mathrm{B})$.

physicians diffuse according to income distribution of the residence and not according to the population distribution. Another study found that physician office locations were affected by the principal factors of proximity to hospitals and in commercial areas. ${ }^{45}$ Most of the hospital are located in central areas, hence this access allows certain patient groups who live in central areas more access to specialists (ie, where stronger socioeconomic levels reside) than those who live in peripheral areas and may increase private $\mathrm{SO}$ utilisation in these areas at the expense of rural areas, and therefore may introduce inequality in access to health services.

Our findings also show that new immigrants tended to use the health fund rather than the supplementary health insurance. A previous study found that new immigrants were more dependent on social benefits obtained from the Israeli National Social Security, as fewer of them had supplementary health insurance. Also, their socioeconomic status was lower. Thus, copayments may be another reason for underutilisation of SOs of new immigrants and those in low socioeconomic status. ${ }^{47}$
Also, higher rates were found in orthopaedics and general surgery, perhaps because the decision to undergo a surgical procedure is more difficult (outcomes of a surgery are often irreversible and are prone to complications). This may reflect the clinical importance patients see in SOs. Indeed, multiple studies have shown discrepancies in clinical judgements ${ }^{12-17}$ and the potential of SOs to reduce unnecessary surgery. ${ }^{18-22}$ This effect might be even more extreme when waiting lists for physicians in the public systems are long and patients are concerned about urgency. In such cases, patients may opt for a private physician, where waiting lists are often shorter.

\section{Policy implications}

It is important to identify specific patient profile groups by their insurance type and devise appropriate mechanisms for access to SOs which will reduce gaps between those groups. ${ }^{48}$ Providing data on SO utilisation by insurance type is important for health policy makers and healthcare providers in order to allocate resources more efficiently and reduce disparities in access to health services and health consumption.

The net expenditure on SOs in 2014 across supplementary insurance provided by the health funds was equivalent to US $\$ 92.6$ million. ${ }^{49}$ The increase of private expenditures on SOs widens the gaps between those who can afford paying privately and those who do not have access to SO or the ability of paying copayments. ${ }^{50-52}$ This increase also raises ethical concerns about physician commitment to fulfil their mission publicly rather than privately.

On the one hand, having a private healthcare system alongside a public system has advantages such as increasing competition in service and quality of care. On the other hand, blurring of the boundaries between the

Table 3 The proportion of second opinion consultations from total consultations by specialty and insurance type $(n=143371)$

\begin{tabular}{lcc}
\hline & $\begin{array}{l}\text { Consultations } \\
\text { via the health } \\
\text { fund }\end{array}$ & $\begin{array}{l}\text { Consultations } \\
\text { via the } \\
\text { supplementary } \\
\text { insurance }\end{array}$ \\
\hline Specialty & $307463(17 \%)$ & $62603(17 \%)$ \\
\hline Orthopaedics & $72560(15 \%)$ & $15164(13 \%)$ \\
General surgery & $266488(13 \%)$ & $61122(13 \%)$ \\
\hline Ophthalmology & $130410(11 \%)$ & $27985(10 \%)$ \\
\hline Ear, nose and throat & $136412(11 \%)$ & $30236(9 \%)$ \\
\hline Dermatology & $21054(10 \%)$ & $5898(9 \%)$ \\
\hline Gastroenterology & $44871(8 \%)$ & $14071(11 \%)$ \\
Cardiology & $54416(7 \%)$ & $20392(12 \%)$ \\
\hline Urology & $26600(3 \%)$ & $7618(9 \%)$ \\
\hline Neurology & &
\end{tabular}

Percentages represent the number of second opinion consultations in each specialty out of the total number of consultations in the specialty. 
two systems may lead to an increase in private expenditure and may harm the principle of equality.

The debate whether SOs should be provided and covered by the government becomes especially interesting in Israel, as the share of private healthcare financing in Israel is one of the highest rates among OECD countries and it has the fastest increase relative to other high-income countries. The 'German Committee' for the strengthening of the public health system proposed some solutions such as splitting the private $\mathrm{SO}$ from the current supplementary insurance structure and providing it as a separate insurance. Currently, there is no policy regarding SOs as a tool for controlling surgical procedures or costs in Israel. ${ }^{381}$ Recently, new regulations were introduced in Israel, limiting physicians who see patients in the public sector to refer them privately, financed by their supplementary insurance. It is still relatively early to consider the implications of these new regulations, although early reports suggest that patients are moving more to the commercial private insurance option. ${ }^{53}$

Health policy regarding SOs is a matter of balancing benefits and costs. Certain patient profiles could have benefited from SOs, but do not have the access in terms of costs and type of insurance they can afford or unavailability of specialists in their residential area. On the other hand, the policy should create the right balance to prevent overuse of SOs.

Another point for decision-makers, the high rates of SOs sought through the Israeli health funds illuminate the need to allocate resources for that purpose, especially in periphery areas, where there is less access to specialists. In the same context, considering the tendency of specialists to reside in central urban areas, it is recommended to incentivise specialties to work in the periphery in order to increase access and availability in those areas.

\section{Strengths and limitations}

This study presents a large-scale population analysis based on an innovative algorithm aimed to study and characterise $\mathrm{SO}$ utilisation by insurance type. This study is unique and first of its kind in exploring the relation between the utilisation of SO provided by the health fund or by supplementary insurance.

Having up-to-date data on SO utilisation by segmentation of insurance type is important to policy makers in order to identify whether SOs are used appropriately and equitably.

While our study was conducted in Israel only, it suggests a generic tool that can become standard and common in modern medical practice worldwide. To the best of our knowledge, all previous studies that evaluated SO utilisation used self-reported surveys with relatively small samples; hence, we could not find any objective data on SO utilisation. Our results possibly reinforce a universal phenomenon. Providing insights from large data sets have relative advantages versus self-reported data by suggesting an objective measurement and reducing the costs of data collection. In addition, such a systematic and objective method of measurement may allow in the future a comparison of outcomes across countries. The current situation which relies on self-reported surveys using different methods of measurement is clearly less suited to obtain this goal. Finally, the relatively large sample size enables statistical analysis in groups that have relatively low representation in the population, such as by sectors, socioeconomic status, etc, especially when it comes with medical services utilisation. On the downside, the nature of this method is unable to shed light on the reasons that led patients to their decisions. Such information, if needed, should still be collected using self-reported surveys. Moreover, it is not always easy to obtain electronic medical records about the entire population. An interesting future research would be to estimate how much data are needed for similar studies, perhaps by applying some power calculations.

Moreover, this study is based on a linkage between rarely linked datasets: universal insurance data and supplementary insurance, containing data on private consultations.

There are several limitations to this study. First, the definition of an $\mathrm{SO}$ as 'consulting with another specialist, in the same specialty' relies on the assumption that consequent consultations with different physicians in the same specialty (eg, two neurologists) in a relatively short period of time, may hint that the second consultation was for obtaining an SO. But patients may approach two physicians in the same domain for other reasons such as a different medical problem or may approach physicians in different domains for the same clinical problem (eg, an orthopaedic surgeon and a neurologist for back pain). We approached this issue by conducting a survey ${ }^{51}$ that explores in depth the reasons for seeking an SO. Another limitation is the lack of data on consultations to private physicians that are not claimed back from the supplementary insurance and the lack of data from private health insurances. Including such data may provide a more comprehensive analysis.

\section{CONCLUSIONS}

This study provides a population-based estimation of $\mathrm{SO}$ utilisation and the characteristics of SO seekers by their insurance type: health fund versus supplementary insurance. Particular patient profiles tend to seek SOs via the health fund rather than the supplementary insurance: women, people aged $40-59$ years, immigrants, people in a low socioeconomic level, those living in periphery and those with chronic conditions. The highest proportion of SO consultations were sought from surgeons, both via the health fund and supplementary insurance. People from the centre of the country and from high socioeconomic status sought more SOs via the supplementary insurance, assuming that medical specialists tend to reside in central urban areas, close to big hospitals. Further research is recommended to examine the availability of medical specialists by specialty and residence. These kinds of data will be essential for policy makers to understand the distribution of specialties who provide SO 
by specialty and residence, and to examine the ratio of service providers per clients by residential area. Likewise, a cost-benefit analysis of outcomes of SOs may be useful to devise further policy on the inclusion of SO in public and private settings.

\section{Author affiliations}

${ }^{1}$ Department of Management, Bar llan University, Ramat Gan, Israel

${ }^{2}$ Department of Industrial Engineering, Tel Aviv University, Tel Aviv, Israel

${ }^{3}$ Department of Industrial Engineering and Management, Ben-Gurion University of the Negev, Beer-Sheva, Israel

${ }^{4}$ Department of Health Systems Management, Ben-Gurion University of the Negev, Beer-Sheva, Israel

${ }^{5}$ Epidemiology, Ben-Gurion University, Tel Aviv, Israel

${ }^{6}$ Clalit Research Institute, Tel Aviv, Israel

${ }^{7}$ Clalit Mushlam Health Insurance, Bnei Brak, Israel

${ }^{8}$ Faculty of Medicine, Tel Aviv University, Tel Aviv, Israel

${ }^{9}$ Department of Primary Care \& Public Health, Imperial College London, London, UK

Acknowledgements The authors would like to thank Professor Nava Pliskin for her valuable comments.

Contributors LS was involved with conception and design, data collection and analysis and drafted the manuscript. ES was involved with data collection and analysis (writing the algorithm code) and contributed to the methods in the manuscript. JSP was involved with acquisition of funding, conception and design, data collection and analysis and revising the manuscript. RDB was involved with conception and design, data collection and analysis and revising the manuscript. ND was involved with acquisition of funding, conception and design, data collection and analysis and revising the manuscript. $\mathrm{IH}$ was involved with conception and design, data collection and analysis and revising the manuscript. GG was involved with acquisition of funding, conception and design, data collection and analysis and drafted the manuscript. All authors read and approved the final manuscript.

Funding Funding was provided by a grant from the Israel National Institution for Health Policy and Health Service Research (NIHP) under grant number R/10/144. GG was supported by the National Institute for Health Research (NIHR) Collaboration for Leadership in Applied Health Research and Care Northwest London (NIHR CLAHRC NWL).

Disclaimer The Israel National Institution for Health Policy and Health Service Research had no role in the design and conduct of the study: collection, management, analysis and interpretation of the data; and preparation, review or approval of the manuscript. The views expressed in this article are those of the author(s) and not necessarily those of the NHS, the NIHR or the Department of Health and Social Care.

\section{Competing interests None declared.}

Patient consent for publication Not required.

Ethics approval The protocol study was approved by the Institutional Helsinki Committee at 'MEIR' Medical Center, for non-clinical studies (approval K2010/137).

Provenance and peer review Not commissioned; externally peer reviewed.

Data sharing statement No additional data are available.

Open access This is an open access article distributed in accordance with the Creative Commons Attribution Non Commercial (CC BY-NC 4.0) license, which permits others to distribute, remix, adapt, build upon this work non-commercially, and license their derivative works on different terms, provided the original work is properly cited, appropriate credit is given, any changes made indicated, and the use is non-commercial. See: http://creativecommons.org/licenses/by-nc/4.0/.

\section{REFERENCES}

1. Mackintosh M, Channon A, Karan A, et al. What is the private sector? Understanding private provision in the health systems of low-income and middle-income countries. Lancet 2016;388:596-605.

2. Barlow J, Roehrich J, Wright S. Europe sees mixed results from public-private partnerships for building and managing health care facilities and services. Health Aff 2013;32:146-54.

3. Filc D, Davidovitch N. Rethinking the private-public mix in health care: analysis of health reforms in Israel during the last three decades. J Health Serv Res Policy 2016;21:249-56.
4. Balicer RD, Shadmi E, Lieberman N, et al. Reducing health disparities: strategy planning and implementation in Israel's largest health care organization. Health Serv Res 2011;46:1281-99.

5. Aaron KF, Clancy CM. Improving quality and reducing disparities: toward a common pathway. JAMA 2003;289:1033-4.

6. Savedoff WD, de Ferranti D, Smith AL, et al. Political and economic aspects of the transition to universal health coverage. Lancet 2012;380:924-32.

7. Chernichovsky D. The Public-Private Mix in the Modern Health Care System - Concepts, Issues, and Policy Options Revisited. National Bureau of Economic Research. 2000 http://www.nber.org/papers/ w7881 (accessed 21 Nov 2013).

8. Chernichovsky D. Reforms Are Needed To Increase Public Funding And Curb Demand For Private Care In Israel's Health System. Health Aff 2013;32:724-33.

9. Choosing Wisely. Choosing Wisely | Promoting conversations between providers and patients. $2018 \mathrm{https}$ ://www.choosingwisely. org/ (accessed 15 May 2019).

10. Tanner M. The Grass is Not Always Greener: A Look at National Health Care Systems around the World. Rochester, NY:: Social Science Research Network. 2008 https://papers.ssrn.com/abstract= 1262978 (accessed 9 Feb 2017).

11. Odeyemi IA, Nixon J. The role and uptake of private health insurance in different health care systems: are there lessons for developing countries? Clinicoecon Outcomes Res 2013;5:109-18.

12. Althabe F, Belizán JM, Villar J, et al. Latin American Caesarean Section Study Group. Mandatory second opinion to reduce rates of unnecessary caesarean sections in Latin America: a cluster randomised controlled trial. Lancet 2004;363:1934-40.

13. Briggs GM, Flynn PA, Worthington M, et al. The role of specialist neuroradiology second opinion reporting: is there added value? Clin Radiol 2008;63:791-5.

14. Kronz JD, Westra WH. The role of second opinion pathology in the management of lesions of the head and neck. Curr Opin Otolaryngol Head Neck Surg 2005;13:81-4.

15. Mellink WA, Dulmen AM, Wiggers T, et al. Cancer patients seeking a second surgical opinion: results of a study on motives, needs, and expectations. J Clin Oncol 2003;21:1492-7.

16. Wieske L, Wijers D, Richard E, et al. Second opinions and tertiary referrals in neurology: a prospective observational study. $J$ Neurol 2008;255:1743-9.

17. Zan E, Yousem DM, Carone M, et al. Second-opinion consultations in neuroradiology. Radiology 2010;255:135-41.

18. Rosenberg SN, Allen DR, Handte JS, et al. Effect of utilization review in a fee-for-service health insurance plan. $N$ Engl J Med 1995;333:1326-31.

19. Ruchlin HS, Finkel ML, McCarthy EG. The efficacy of secondopinion consultation programs: a cost-benefit perspective. Med Care 1982;20:3-20.

20. McCarthy EG, Finkel ML. Second consultant opinion for elective orthopedic surgery. Am J Public Health 1981;71:1233-6.

21. Lenza M, Buchbinder R, Staples MP, et al. Second opinion for degenerative spinal conditions: an option or a necessity? A prospective observational study. BMC Musculoskelet Disord 2017; $18: 354$.

22. Oliveira IO, Lenza M, Vasconcelos RA, et al. Second opinion programs in spine surgeries: an attempt to reduce unnecessary care for low back pain patients. Braz J Phys Ther 2019;23:1-2.

23. Tam KF, Cheng DK, Ng TY, et al. The behaviors of seeking a second opinion from other health-care professionals and the utilization of complementary and alternative medicine in gynecologic cancer patients. Support Care Cancer 2005;13:679-84.

24. Axon A, Hassan M, Niv Y, et al. Ethical and legal implications in seeking and providing a second medical opinion. Dig Dis 2008;26:11-17.

25. Wagner TH, Wagner LS. Who gets second opinions? Health Aff 1999;18:137-45.

26. National Patient Safety Foundation. Public opinion of patient safety issues. $1997 \mathrm{http}: / /$ www.npsf.org/wp-content/uploads/2011/10/ Public_Opinion_of_Patient_Safety_Issues.pdf (accessed 30 Apr 2012).

27. Gertman PM, Stackpole DA, Levenson DK, et al. Second opinions for elective surgery. The mandatory medicaid program in Massachusetts. N Engl J Med 1980;302:1169-74.

28. medicare.gov. Second Surgical Opinion Coverage. medicare.gov. 2017 https://www.medicare.gov/coverage/second-surgical-opinions (accessed 15 May 2019).

29. Ridic G, Gleason S, Ridic O. Comparisons of health care systems in the United States, Germany and Canada. Mater Sociomed 2012;24:112. 
30. NHS Choices. How do I get a second opinion? - Health questions - NHS Choices. 2012 http://www.nhs.uk/chq/Pages/910.aspx? CategoryID=68\&SubCategorylD=156 (accessed 18 Feb 2013).

31. Clauson J, Hsieh YC, Acharya S, et al. Results of the Lynn Sage Second-Opinion Program for local therapy in patients with breast carcinoma. Changes in management and determinants of where care is delivered. Cancer 2002;94:889-94.

32. Bin Nun G. Private health insurance policies in Israel: a report on the 2012 Dead Sea Conference. Isr J Health Policy Res 2013;2:25.

33. Brammli-Greenberg S, Waitzberg R, Medina-Artom T, et al. Lowbudget policy tool to empower Israeli insureds to demand their rights in the healthcare system. Health Policy 2014;118:279-84.

34. Greenfield G, Pliskin JS, Feder-Bubis P, et al. Patient-physician relationships in second opinion encounters - the physicians' perspective. Soc Sci Med 2012;75:1202-12.

35. Israeli Ministry of Health IM of. A public report on supplementary health programs of the Israeli Health Funds in 2011. $2011 \mathrm{http}: / /$ www.health.gov.il/PublicationsFiles/sbn2011_17122012.pdf.

36. Payne VL, Singh H, Meyer AN, et al. Patient-initiated second opinions: systematic review of characteristics and impact on diagnosis, treatment, and satisfaction. Mayo Clin Proc 2014;89:687-96.

37. Shmueli L, Shmueli E, Pliskin JS, et al. Second Medical Opinion: Utilization Rates and Characteristics of Seekers in a General Population. Med Care 2016;54:921-8.

38. Charlson ME, Pompei P, Ales KL, et al. A new method of classifying prognostic comorbidity in longitudinal studies: development and validation. J Chronic Dis 1987;40:373-83.

39. Kraemer HC, Morgan GA, Leech NL, et al. Measures of clinical significance. J Am Acad Child Adolesc Psychiatry 2003;42:1524-9.

40. Rosen B, Waitzberg R, Merkur S. Israel: health system review. Health Syst Transit 2015;17:1-212.

41. Woolf SH, Braveman P. Where health disparities begin: the role of social and economic determinants--and why current policies may make matters worse. Health Aff 2011;30:1852-9.
42. Regidor E, Martínez D, Calle ME, et al. Socioeconomic patterns in the use of public and private health services and equity in health care. BMC Health Serv Res 2008;8:183.

43. Filc D, Davidovich N, Novack L, et al. Is socioeconomic status associated with utilization of health care services in a single-payer universal health care system? Int J Equity Health 2014;13:115.

44. Rosen B, Brammli-Greenberg S, Gross R, et al. When co-payments for physician visits can affect supply as well as demand: findings from a natural experiment in Israel's national health insurance system. Int J Health Plann Manage 2011;26:e68-84.

45. Kaplan RS, Leinhardt S. Determinants of physician office location. Med Care 1973;11:406-15.

46. Sibley LM, Weiner JP. An evaluation of access to health care services along the rural-urban continuum in Canada. BMC Health Serv Res 2011;11:20.

47. Davidovitch N, Filc D, Novack L, et al. Immigrating to a universal health care system: utilization of hospital services by immigrants in Israel. Health Place 2013;20:13-18.

48. Ruetters D, Keinki C, Schroth S, et al. Is there evidence for a better health care for cancer patients after a second opinion? A systematic review. J Cancer Res Clin Oncol 2016;142:1521-8.

49. Israeli Ministry of Health IM of $\mathrm{H}$. A public report on supplementary health programs of the Israeli Health Funds in 2014. 2015 http:// www.health.gov.il/PublicationsFiles/shaban2014_03012016.pdf.

50. Vashitz G, Davidovitch N, Pliskin JS. [Second medical opinions]. Harefuah 2011;150:105-10. 207.

51. Shmueli L, Davidovitch N, Pliskin JS, et al. Seeking a second medical opinion: composition, reasons and perceived outcomes in Israel. Isr J Health Policy Res 2017;6:67.

52. Shmueli L, Davidovitch N, Pliskin JS, et al. Reasons, perceived outcomes and characteristics of second-opinion seekers: are there differences in private vs. public settings? BMC Health Serv Res 2019;19:238.

53. Linder-Ganz R. Israel's Private Medical-care Reforms to Come Into Effect. Haaretz. 2016 https://www.haaretz.com/israel-news/ business/.premium-israel-s-private-medical-care-reforms-to-comeinto-effect-1.5402942 (accessed 17 May 2019). 